\title{
Tobacco use and psychosis risk in persons at clinical high risk
}

\author{
Heather B. Ward ${ }^{1} \odot \mid$ Michael T. Lawson ${ }^{2}$ | Jean Addington ${ }^{3} \odot$ | Carrie E. Bearden ${ }^{4}$ | \\ Kristin S. Cadenhead ${ }^{5}$ ๑ | Tyrone D. Cannon ${ }^{6}$ ๑) | Barbara A. Cornblatt ${ }^{7}$ ( ) Clark D. Jeffries ${ }^{8} \mid$

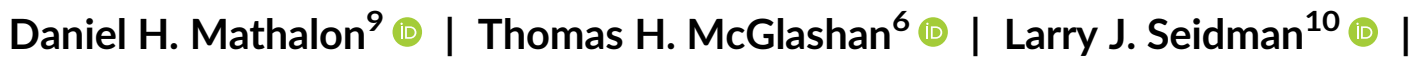 \\ Ming T. Tsuang ${ }^{5}$ ๑ | Elaine F. Walker ${ }^{11} \mid$ Scott W. Woods ${ }^{6}$ | Diana O. Perkins ${ }^{12}$ (1)
}

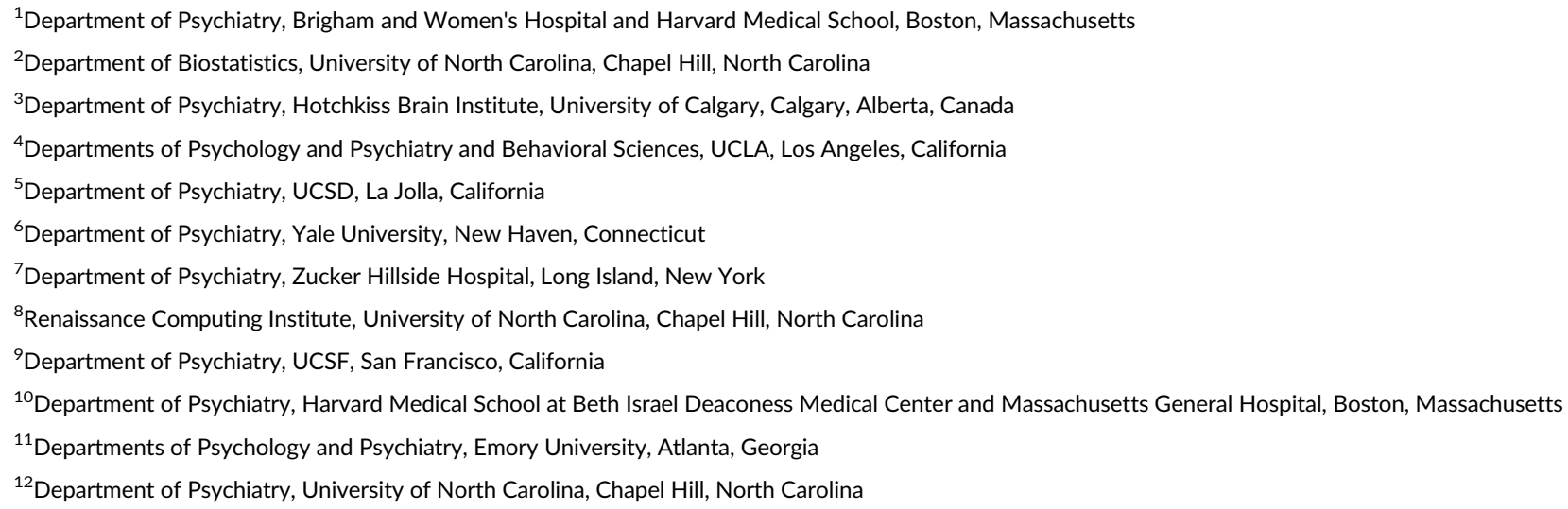

\section{Correspondence}

Diana O. Perkins, The University of North Carolina at Chapel Hill, Campus Box \#7160, Chapel Hill, North Carolina 27599-7160.

Email: diana_perkins@med.unc.edu

Funding information Commonwealth of Massachusetts, Grant/ Award Number: SCDMH82101008006; National Institute of Environmental Health Sciences, Grant/Award Number: T32ES007018; National Institute of Mental Health, Grant/Award Number: K24 MH76191 P50 MH066286 P50 MH080272R01 MH6072OU01 MH081857-05 U01 MH081902 U01 MH081928U01 MH081984 U01 MH081988 U01 MH082004 U01 $\mathrm{MH} 082022$
Aim: To evaluate the role of tobacco use in the development of psychosis in individuals at clinical high risk.

Method: The North American Prodrome Longitudinal Study is a 2-year multi-site prospective case control study of persons at clinical high risk that aims to better understand predictors and mechanisms for the development of psychosis. The cohort consisted of 764 clinical high risk and 279 healthy comparison subjects. Clinical assessments included tobacco and substance use and several risk factors associated with smoking in general population studies.

Results: Clinical high risk subjects were more likely to smoke cigarettes than unaffected subjects (light smoking odds ratio $[\mathrm{OR}]=3.0,95 \%$ confidence interval $[\mathrm{Cl}]=1.9-5$; heavy smoking $\mathrm{OR}=4.8,95 \% \mathrm{Cl}=1.7-13.7)$. In both groups, smoking was associated with mood, substance use, stress and perceived discrimination and in clinical high risk subjects with childhood emotional neglect and adaption to school. Clinical high risk subjects reported higher rates of several factors previously associated with smoking, including substance use, anxiety, trauma and perceived discrimination. After controlling for these potential factors, the relationship between clinical high risk state and smoking was no longer significant (light smoking $\mathrm{OR}=0.9,95 \% \mathrm{Cl}=0.4-2.2$; heavy smoking $\mathrm{OR}=0.3,95 \%$ $\mathrm{Cl}=0.05-2.3$ ). Moreover, baseline smoking status (hazard ratio $[\mathrm{HR}]=1.16,95 \% \mathrm{Cl}=0.82-1.65$ ) and categorization as ever smoked ( $\mathrm{HR}=1.3,95 \% \mathrm{Cl}=0.8-2.1)$ did not predict time to conversion.

Conclusion: Persons at high risk for psychosis are more likely to smoke and have more factors associated with smoking than controls. Smoking status in clinical high risk subjects does not predict conversion. These findings do not support a causal relationship between smoking and psychosis.

\section{KEYWORDS}

clinical high risk, psychosis, schizophrenia, substance use disorder, tobacco 


\section{1 | INTRODUCTION}

One of the most consistent observations in persons with schizophrenia and other psychotic disorders is a high rate of tobacco use, estimated at 3- to 6-fold that of the general population (de Leon \& Diaz, 2005; Gurillo, Jauhar, Murray, \& MacCabe, 2015). Initiation of smoking occurs before psychosis symptoms emerge for about $75 \%$ of persons with schizophrenia (de Leon \& Diaz, 2005), and prospective population-based cohort studies (Kendler, Lonn, Sundquist, \& Sundquist, 2015; Riala, Hakko, Isohanni, Pouta, \& Rasanen, 2005; Sorensen, Mortensen, Reinisch, \& Mednick, 2011; Weiser et al., 2004; Zammit et al., 2003) find that risk of schizophrenia is about doubled for tobacco smokers (Gurillo et al., 2015). Based on the observed temporal precedence and that higher levels of tobacco use are associated with higher risk of subsequent schizophrenia (Kendler et al., 2015; Weiser et al., 2004), several researchers propose that there is a causal relationship between smoking tobacco and the development of a psychotic disorder (Alderson \& Lawrie, 2015; Gage \& Munafo, 2015; Gurillo et al., 2015; Kendler, Ohlsson, Mezuk, Sundquist, \& Sundquist, 2016; Wium-Andersen, Orsted, \& Nordestgaard, 2015).

These same investigators (Alderson \& Lawrie, 2015, Gage \& Munafo, 2015, Gurillo et al., 2015, Kendler et al., 2016, WiumAndersen et al., 2015) acknowledge, however, the many challenges to establishing causality in observational studies, especially that of confounding. Factors associated with increased risk of smoking initiation and dependence in the general population, if also associated with psychosis risk, could confound associations of smoking and schizophrenia. General population factors associated with smoking include depression, general anxiety, social anxiety, low self-esteem, impulsivity, trauma, stress, alcohol use, poor academic performance and low socioeconomic status (SES) (Balk, Lynskey, \& Agrawal, 2009; Johnson \& Hoffmann, 2000; Kushner, Menary, Maurer, \& Thuras, 2012; Leventhal et al., 2012; Leventhal \& Zvolensky, 2015; Liu, 2003; Lynch, Kaplan, \& Salonen, 1997; O'Loughlin, Dugas, O'Loughlin, Karp, \& Sylvestre, 2014; Otten, Bosma, \& Swinkels, 1999; Patton et al., 1998; Sonntag, Wittchen, Hofler, Kessler, \& Stein, 2000).

The North American Prodrome Longitudinal Study is a collaborative effort to determine predictors and mechanisms for the development of psychosis in persons meeting clinical high risk diagnostic criteria (Addington et al., 2007). Using data from our completed 2-year prospective cohort (Addington et al., 2012; Perkins et al., 2015), we aimed to evaluate the hypothesized causal role of tobacco use in the development of psychosis.

\section{2 | METHODS}

\section{1 | Participants}

Participants included 764 clinical high-risk subjects and 279 unaffected comparison (UC) subjects. All high-risk participants were required to meet the Criteria of Psychosis-Risk Syndromes (COPS) based on the structured interview for psychosis-risk syndromes (SIPS) (McGlashan, Walsh, \& Woods, 2010). Twenty-one subjects who did not meet
COPS criteria were included but met alternate criteria. Subjects were excluded if they met criteria for any current or lifetime Axis I psychotic disorder, intelligence quotient $<70$ based on the Wechsler Abbreviated Scale of Intelligence (Wechsler, 1999), past or current history of central nervous system disorder, or met Diagnostic and Statistical Manual of Mental Disorder, Fourth Edition (DSM-IV) criteria for current substance dependence (excluding nicotine) disorder. Comparison subjects were also excluded if they had a first-degree relative with a current or past psychotic disorder, met criteria for any high-risk syndrome, current or past DSM-IV psychotic disorder or cluster A personality disorder or were currently using psychotropic medication (Addington et al., 2012).

Clinical assessments were done every 6 months and subjects followed for up to 2 years. Severity of positive, negative, disorganized and general symptoms was rated on the Scale of Psychosis-Risk Symptoms (SOPS). Conversion to psychosis was based on the SIPS interview, defined as meeting the Presence of Psychosis Syndrome (POPS) criteria.

Informed consent was obtained from eligible subjects who were judged to be fully competent to provide consent. Participants under age 18 provided informed assent as well as parental consent. The study was approved by the institutional review boards of all eight sites.

\subsection{1 | Assessments}

Our primary independent variable was based on the frequency of tobacco use as measured by the Alcohol Use Scale/Drug Use Scale (AUS/DUS) (Drake, Mueser, \& McHugo, 1996b; Drake, Rosenberg, \& Mueser, 1996a). The original scoring was measured by cigarettes per day $(0=$ no use, 1 = occasionally, 2 = less than 10 per day, $3=11-25$ per day, $4=$ more than 25 per day) that was rescaled for this analysis to be consistent with previous studies $(0=$ nonsmoker, 1 or 2 = light smoker, 3 or 4 = heavy smoker).

Cigarette use was also assessed as part of the olfaction clinical assessment, where subjects were asked if they "ever smoked." If affirmed subjects were asked about the age they started smoking, the number of years they have smoked, the overall average number of cigarettes per day they have smoked, and if they currently smoke (if "no" what age they stopped smoking, if "yes" the number of cigarettes per day they currently smoke). If baseline data were missing, age of onset of smoking and lifetime smoking were used from collection at a later visit if occurring at an age prior to study entry.

We identified variables in the study assessment battery that have been associated with smoking initiation or dependence as reviewed in the introduction; these included demographic variables (sex, SES and age), substance use, academic and social function, anxiety and depression symptoms, trauma history and stressful life events.

Socioeconomic status was measured by education completed by each parent $(1$ = No schooling, 2 = Some primary school, 3 = Completed primary school, $4=$ Some high school, $5=$ Completed high school, 6 = Some college/technical school/undergraduate, 7 = Completed graduate/professional school, $8=$ Some graduate/professional school, 9 = Completed graduate/professional school). 
We assessed marijuana, alcohol, and other substance use in past month with the AUS/DUS $(0=$ no use, $1=$ once or twice per month, 2 = 3-4 times per month, 3 = 1-2 times per week, 4 = 3-4 times per week, 5 = almost daily). Substance use was considered an ordinal variable.

Academic and social function was assessed using the Premorbid Adjustment Scale (PAS) (Cannon-Spoor, Potkin, \& Wyatt, 1982; van Mastrigt \& Addington, 2002).

Depression was assessed with the Calgary Depression Scale for Schizophrenia (CDSS) (Addington, Addington, \& Matickatyndale, 1993), and anxiety symptoms with the Social Interaction Anxiety Scale (SIAS) and Social Anxiety Scale (SAS) (Olivares, Garcia-Lopez, \& Hidalgo, 2001).

We evaluated the experience of trauma and abuse with the Childhood Trauma and Abuse Scale (Janssen et al., 2004). Life stress was assessed with a modified version of the Psychiatric Epidemiology Research Interview Life Events Scale (Dohrenwend, Krasnoff, Askenasy, \& Dohrenwend, 1978) and the Daily Stress Inventory (Brantley, Waggoner, Jones, \& Rappaport, 1987). Perceived discrimination was assessed using an adapted self-report measure (Janssen et al., 2003).

The PAS scholastic performance and adaptation to school, CDSS total score, SIAS total score, SAS total anxiety score, daily stressors total score, total life events, and total lifetime perceived discrimination were considered continuous variables. Trauma variables were considered categorical variables.

\subsection{Statistical analysis}

For continuous variables, we compared group averages using the twotailed student $t$ test. For categorical or ordinal variables, we used the $\chi^{2}$ test, where small cell sizes threatened the validity of asymptotic theory, we used the exact Pearson $\chi^{2}$ test.
We assessed the univariate associations between tobacco use and potential tobacco use risk factors with the exact MantelHaenzel $\chi^{2}$ test if the independent variable was categorical, the exact Cochran-Armitage test of trend if the independent variable was ordinal, the exact Pearson $\chi^{2}$ test if the independent variable was ordinal, and the Kruskal-Wallis test if the independent variable was continuous.

We use logistic regression to evaluate the effect of tobacco use on clinical high risk state, while adjusting for potential confounders with clinical high risk state as the outcome. All variables with a univariate association with clinical high risk state were candidate covariates. Tobacco use, marijuana use, alcohol use, age, ethnicity, academic performance, academic adjustment, depression, anxiety, social anxiety, daily stressors, life events and perceived discrimination were selected as covariates.

We used the cox proportional hazards model to determine if smoking predicted development of psychosis in persons at clinical high risk, and show Kaplan-Meyer survival curves stratified by smoking (none, light, heavy).

All analyses were carried out in SAS, version 9.4 (SAS Institute, Cary, North California).

\section{3 | RESULTS}

A total of 1043 participants (764 clinical high risk and 279 UC subjects) were enrolled in the study. We included 587 clinical high risk and 274 unaffected subjects in this analysis (see Figure 1, consort diagram, for exclusion reasons). Within each group, there were no

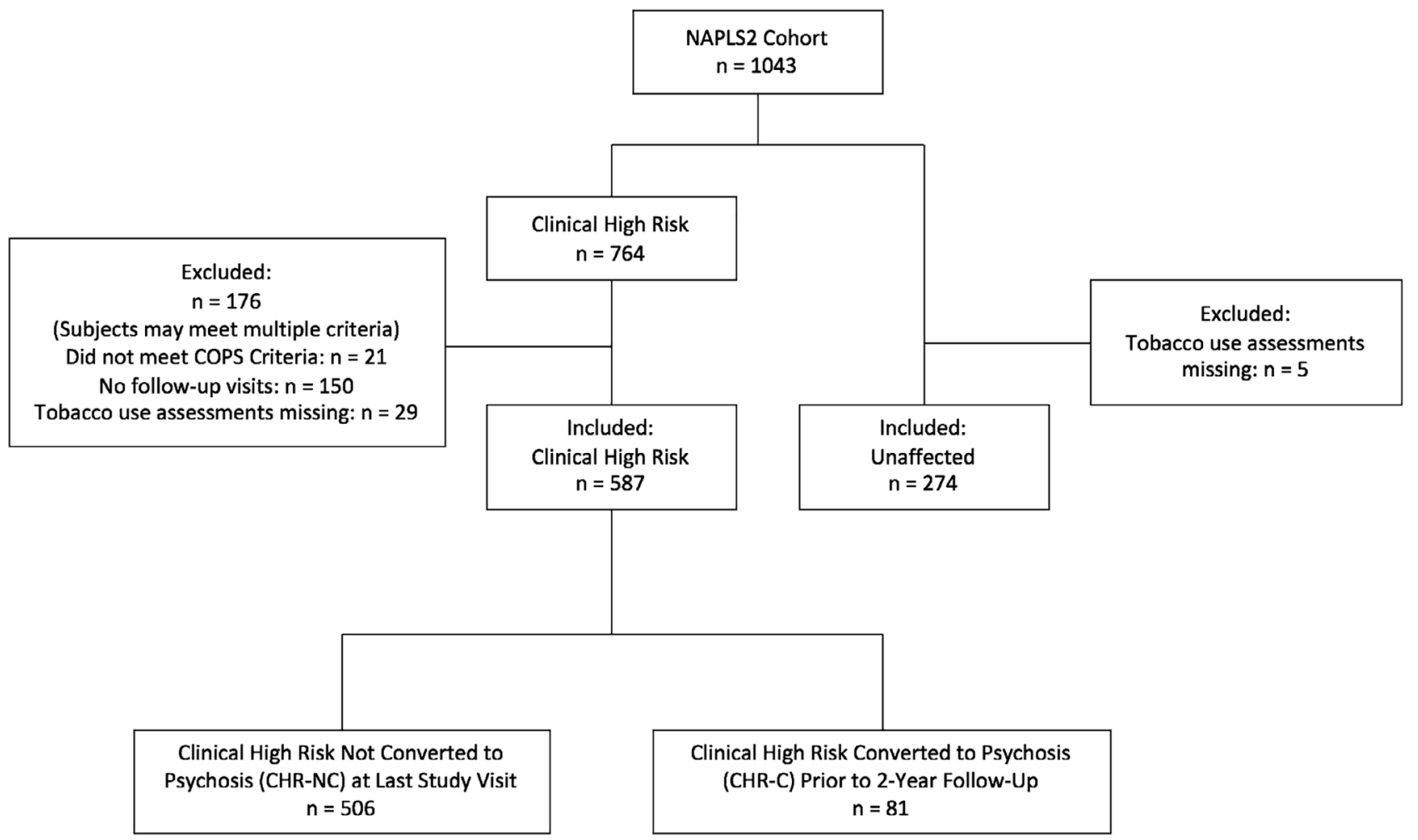

FIGURE 1 CONSORT diagram. COPS, criteria of psychosis-risk syndromes 
significant differences between subjects who were excluded compared to those who were included for demographics, smoking or illness severity (Table 1).

\section{1 | Tobacco use in clinical high risk and unaffected subjects}

Compared to unaffected subjects, a greater proportion of clinical high risk subjects reported current smoking and history of ever smoking (light smoking odds ratio $[\mathrm{OR}]=3.0,95 \%$ confidence interval $[\mathrm{Cl}]=$ 1.9-5; heavy smoking $\mathrm{OR}=4.8,95 \% \mathrm{Cl}=1.7-13.7$ ). However, for smokers, there were no differences between groups for the age started smoking (high risk mean $=16.0, \mathrm{sd}=2.8$, unaffected mean $=16.7, \mathrm{sd}=2.8, t(79.4)=-1.8, P$ value $=0.082$, number of years smoked (high risk mean $=3.5, \mathrm{sd}=3.5$, unaffected mean $=3.5$, $s d=3.2, t(69.3)=-0.02, P$ value $=0.98$ ), or lifetime average (high risk median $=3.5$, interquartile range $[I Q R]=9$, unaffected median $=2$, $\mathrm{IQR}=4$, Wilcoxon statistic $=4942.5, \mathrm{P}$ value $=0.068)$. When controlling for age at onset of clinical high risk symptoms, there was no difference in the proportion of smokers between groups (OR $=1.195$, $95 \% \mathrm{Cl}=1.15-1.24)$.

In the clinical high risk group, initiation of smoking occurred a median of 2 years prior to meeting diagnostic criteria $(I Q R=4)$, and preceded onset of high risk state for $157 / 187$ (84\%) of subjects.

During study participation 15/273 (5.49\%), clinical high risk individuals stopped smoking and 28/273 (10.26\%) started smoking, which did not significantly differ from unaffected subjects, where 4/134 (2.99\%) stopped smoking and 12/134 (8.96\%) started smoking.

\section{2 | Factors associated with smoking and with group}

Smoking was associated with older age, marijuana use, alcohol use, cocaine use, hallucinogen use, "3,4-Methylenedioxymethamphetamine (MDMA)" use, perceived discrimination and stressful life events in both groups, and with scholastic performance, adaptation to school, and emotional neglect in clinical high risk subjects (Table 2).

Several of these variables were more common or rated as more severe in clinical high risk as compared with unaffected subjects (Table 2), including marijuana use, depression, anxiety, social anxiety, scholastic performance, adaptation to school, perceived discrimination, daily stressors, stressful life events, psychological bullying, physical bullying, emotional neglect, psychological abuse, physical abuse and sexual abuse. Clinical high risk subjects were younger and reported less alcohol use compared to unaffected subjects. In unaffected subjects, all drug use and daily stressors were associated with smoking.

Although clinical high risk subjects were more likely to smoke compared to unaffected subjects, the relationship between high risk state and smoking became non-significant after we controlled for certain potential confounders. When we considered confounders individually, such as depression, anxiety and school adjustment, the odds ratios between smoking and clinical high risk state were no longer

TABLE 1 Demographic characteristics by group

\begin{tabular}{|c|c|c|c|c|c|c|c|c|c|c|c|c|c|}
\hline \multirow[b]{3}{*}{ Variable } & \multicolumn{3}{|c|}{ Clinical high risk included } & \multicolumn{4}{|c|}{ Clinical high risk excluded } & \multicolumn{3}{|c|}{ Unaffected included } & \multicolumn{3}{|c|}{ Unaffected excluded } \\
\hline & \multicolumn{3}{|c|}{$n=587$} & \multicolumn{4}{|c|}{$n=176$} & \multicolumn{3}{|l|}{$n=274$} & \multicolumn{3}{|l|}{$n=5$} \\
\hline & Mean & \multicolumn{2}{|c|}{ SD } & Mean & & \multicolumn{2}{|c|}{ SD } & Mean & \multicolumn{2}{|l|}{ SD } & Mean & \multicolumn{2}{|l|}{ SD } \\
\hline SES & 6.82 & \multicolumn{2}{|c|}{1.79} & 6.33 & & \multicolumn{2}{|c|}{2.14} & 7.19 & \multicolumn{2}{|l|}{1.48} & 6.40 & \multicolumn{2}{|l|}{1.82} \\
\hline Father's education & 6.29 & \multicolumn{2}{|c|}{1.74} & 6.07 & & \multicolumn{2}{|c|}{1.71} & 6.54 & \multicolumn{2}{|l|}{1.64} & 6.00 & 2.55 & \\
\hline & & $\%$ & $\mathrm{n}$ & & $\%$ & & $\mathbf{n}$ & $\%$ & & $\mathrm{n}$ & $\%$ & & $\mathrm{n}$ \\
\hline Caucasian & & 58.3 & 342 & & 54.3 & & 95 & 54.4 & & 149 & 60.0 & & 3 \\
\hline South or central Am & & 4.1 & 24 & & 5.7 & & 10 & 4.7 & & 13 & 0 & & 0 \\
\hline African & & 15.2 & 89 & & 16.6 & & 29 & 17.2 & & 47 & 20.0 & & 1 \\
\hline BIPS & & 3.1 & 18 & & 1.1 & & 2 & & & & & & \\
\hline GRD & & 11.9 & 70 & & 7.9 & & 14 & & & & & & \\
\hline Baseline smoking st & & $\%$ & $n$ & & $\%$ & & $\mathrm{n}$ & $\%$ & & $n$ & $\%$ & & $n$ \\
\hline None & & 75.0 & 440 & & 79.1 & & 117 & 90.9 & & 249 & & & \\
\hline Light & & 19.2 & 113 & & 16.2 & & 24 & 7.7 & & 21 & & & \\
\hline Heavy & & 5.8 & 34 & & 4.7 & & 7 & 1.5 & & 4 & & & \\
\hline Ever smoked & & 38.6 & 200 & & 38.7 & & 41 & 22.9 & & 56 & 33.3 & & 1 \\
\hline
\end{tabular}

Abbreviations: APS, Attenuated Psychotic Symptoms; BIPS, Brief Intermittent Psychotic Symptoms; GRD, Genetic Risk and Deterioration; SES, socioeconomic status. 
TABLE 2 Factors associated with smoking and with group status

\begin{tabular}{|c|c|c|c|c|c|c|c|c|c|c|}
\hline \multirow{3}{*}{ Variable } & & \multicolumn{5}{|c|}{ Relationship to group } & \multicolumn{4}{|c|}{ Relationship to smoking } \\
\hline & & \multicolumn{2}{|c|}{ Clinical high risk } & \multicolumn{2}{|c|}{ Unaffected } & \multirow[b]{2}{*}{$P$ value } & \multicolumn{2}{|c|}{ Clinical high risk } & \multicolumn{2}{|c|}{ Unaffected } \\
\hline & & Mean & SD & Mean & SD & & $\begin{array}{l}\text { Statistic } \\
32.3\end{array}$ & $\begin{array}{l}P \text { value } \\
<0.0001\end{array}$ & $\begin{array}{l}\text { Statistic } \\
12.1\end{array}$ & $\begin{array}{l}P \text { value } \\
0.0024\end{array}$ \\
\hline Parental education & & & & & & & & & & \\
\hline Mother's education & & 6.37 & 1.63 & 6.84 & 1.48 & $<0.0001$ & 0.71 & 0.70 & 0.72 & 0.70 \\
\hline Father's education & & 6.29 & 1.74 & 6.54 & 1.64 & 0.042 & 0.67 & 0.72 & 1.3 & 0.53 \\
\hline Highest & & 6.97 & 1.60 & 7.24 & 1.41 & 0.015 & 0.03 & 0.99 & 0.26 & 0.88 \\
\hline Substance Use & $\%$ & $\mathrm{n}$ & $\%$ & $\mathrm{n}$ & & $P$ value & Statistic & $P$ value & Statistic & $P$ value \\
\hline Marijuana & & & & & & & & & & \\
\hline No use & 74.3 & 436 & 89.4 & 245 & & $<0.0001$ & 121.1 & $<0.0001$ & 11.4 & 0.0057 \\
\hline $1-2 x /$ month & 10.7 & 63 & 5.8 & 16 & & & & & & \\
\hline Daily & 3.4 & 20 & 0.7 & 2 & & & & & & \\
\hline Any use & 25.7 & 151 & 10.6 & 29 & & $<0.0001$ & -9.45 & $<0.0001$ & -3.31 & 0.0046 \\
\hline Substance Use & $\%$ & $\mathrm{n}$ & $\%$ & $\mathrm{n}$ & & $P$ value & Statistic & $P$ value & Statistic & $P$ value \\
\hline Alcohol & & & & & & & & & & \\
\hline No use & 60.3 & 354 & 48.5 & 133 & & 0.0019 & 92.6 & $<0.0001$ & 30.07 & $<0.0001$ \\
\hline $1-2 x /$ month & 18.1 & 106 & 21.9 & 60 & & & & & & \\
\hline $3-4 x /$ month & 6.1 & 36 & 10.6 & 29 & & & & & & \\
\hline $1-2 x /$ week & 9.9 & 58 & 13.9 & 38 & & & & & & \\
\hline $3-4 x /$ week & 3.9 & 23 & 5.1 & 14 & & & & & & \\
\hline Huffing & 0.3 & 2 & 0.7 & 2 & & 0.60 & -0.47 & 1 & -3.61 & 0.035 \\
\hline MDMA & 1.9 & 11 & 0.7 & 2 & & 0.25 & -3.51 & 0.0026 & -3.61 & 0.035 \\
\hline Opiates & 0.9 & 5 & 0.7 & 2 & & 1 & -1.92 & 0.077 & -3.61 & 0.035 \\
\hline PCP & 0.3 & 2 & 0.7 & 2 & & 0.60 & -0.47 & 1 & -3.61 & 0.035 \\
\hline Substance Use & & Mean & SD & Mean & SD & $P$ value & Statistic & $P$ value & Statistic & $P$ value \\
\hline Mood & & & & & & & & & & \\
\hline Depression & & 5.89 & 4.75 & 0.58 & 1.44 & $<0.0001$ & 3.33 & 0.19 & 3.17 & 0.21 \\
\hline Anxiety & & 47.47 & 13.4 & 28.66 & 4.81 & $<0.0001$ & 4.72 & 0.09 & 4.65 & 0.098 \\
\hline Social anxiety & & 31.22 & 17.5 & 8.99 & 8.69 & $<0.0001$ & 2.46 & 0.29 & 4.36 & 0.11 \\
\hline Scholastic performance & & 12.02 & 5.34 & 7.75 & 4.21 & $<0.0001$ & 6.05 & 0.049 & 2.02 & 0.36 \\
\hline Adaptation to school & & 9.30 & 4.74 & 4.85 & 2.51 & $<0.0001$ & 26.3 & $<0.0001$ & 3.80 & 0.15 \\
\hline Perceived discrimination & & 2.81 & 2.21 & 1.72 & 1.75 & $<0.0001$ & 7.86 & 0.020 & 8.51 & 0.014 \\
\hline Daily stressors & & 74.45 & 59.6 & 29.31 & 29.0 & $<0.0001$ & 0.91 & 0.63 & 7.70 & 0.021 \\
\hline Stressful events & & 26.91 & 23.6 & 20.45 & 11.7 & $<0.0001$ & 33.3 & $<0.0001$ & 8.47 & 0.015 \\
\hline Substance Use & & Mean & SD & Mean & SD & $P$ value & Statistic & $P$ value & Statistic & $P$ value \\
\hline Childhood trauma & & & & & & & & & & \\
\hline Psychological bullying & & 58.7 & 339 & 27.5 & 74 & $<0.0001$ & 8.03 & 0.09 & 6.36 & 0.15 \\
\hline Physical bullying & & 27.0 & 156 & 10.8 & 29 & $<0.0001$ & 3.66 & 0.46 & 7.77 & 0.10 \\
\hline Emotional neglect & & 39.8 & 230 & 6.3 & 17 & $<0.0001$ & 10.8 & 0.028 & 5.61 & 0.19 \\
\hline
\end{tabular}

Abbreviations: GHB, gamma-hydroxybutyric acid; MDMA, 3,4-methylenedioxymethamphetamine; PCP, phencyclidine. 
TABLE 3 Smoking association with clinical high-risk status after controlling on individual variables

\begin{tabular}{|lcccc} 
Control variable & $\begin{array}{l}\text { Light } \\
\text { smoking OR }\end{array}$ & 95\% Cl & $\begin{array}{l}\text { Heavy } \\
\text { smoking OR }\end{array}$ & $95 \% \mathrm{Cl}$ \\
\hline Age & 3.4 & $2.1-5.6$ & 5.7 & $2.0-16.5$ \\
\hline Maternal education & 3.1 & $1.9-5.0$ & 4.9 & $1.7-14.1$ \\
\hline Paternal education & 3.2 & $1.9-5.3$ & 4.3 & $1.5-12.4$ \\
\hline Marijuana & 2.3 & $1.4-3.8$ & 3.8 & $1.3-11.0$ \\
\hline Alcohol & 4.2 & $2.5-7.1$ & 8.1 & $2.7-24.0$ \\
\hline Depression* & 2.3 & $1.3-4.1$ & 2.7 & $0.8-9.2$ \\
\hline Anxiety* & 1.6 & $0.8-3.2$ & 1.6 & $0.4-6.1$ \\
\hline Scholastic performance & 2.6 & $1.6-4.4$ & 3.6 & $1.2-10.7$ \\
\hline Adaptation to school* & 1.9 & $1.1-3.3$ & 1.7 & $0.6-5.4$ \\
\hline Perceived discrimination & 2.7 & $1.6-4.5$ & 4.1 & $1.4-11.7$ \\
\hline Daily stressors* & 2.2 & $1.3-3.9$ & 4.9 & $1.4-16.9$ \\
\hline Stressful events & 2.6 & $1.5-4.2$ & 3.8 & $1.3-10.9$ \\
\hline Physical bullying & 2.9 & $1.8-4.8$ & 4.3 & $1.5-12.3$ \\
\hline Emotional neglect* & 2.8 & $1.7-4.7$ & 3.2 & $1.1-9.4$ \\
\hline Psychological abuse & 2.9 & $1.8-4.9$ & 3.5 & $1.2-10.2$ \\
\hline
\end{tabular}

Abbreviations: $\mathrm{Cl}$, confidence interval; OR, odds ratio.

*Covariates that significantly reduced association between smoking and clinical high-risk status $(P<0.05)$.

significant (Table 3). When a forward selection regression model chose multiple factors, the odds ratio between smoking and clinical high risk state was no longer significant (light smoking OR $=0.9,95 \%$ $\mathrm{Cl}=0.4-2.2$; heavy smoking $\mathrm{OR}=0.3,95 \% \mathrm{Cl}=0.05-2.3$ ) (Figure 2).

\section{3 | Tobacco use and psychosis risk}

Smoking status (none, light or heavy) at baseline did not predict time to conversion ( $\mathrm{HR}=1.0,95 \% \mathrm{Cl}=0.7-1.5)$ (Figure 3). In addition,

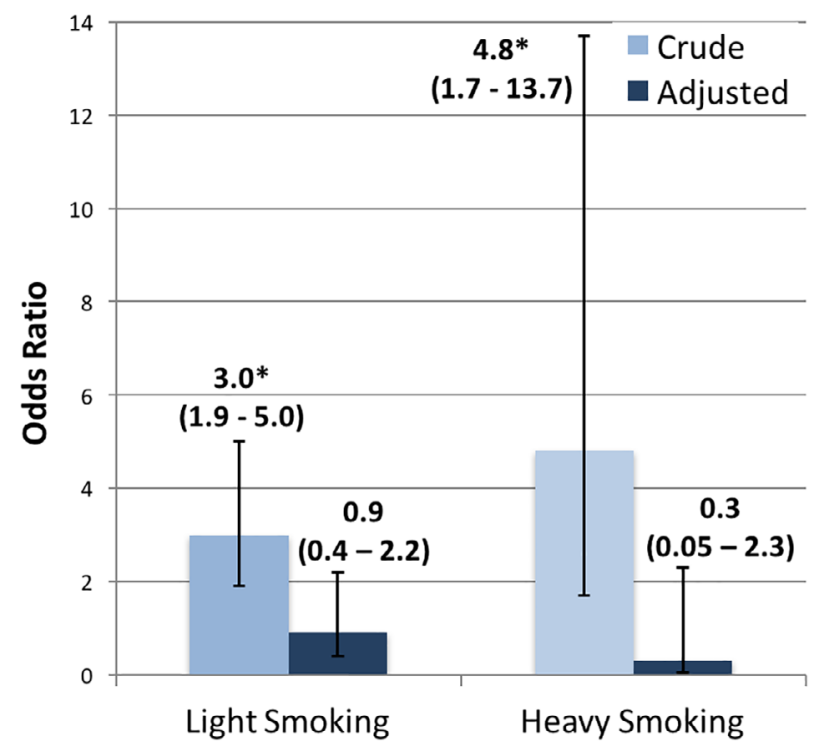

FIGURE 2 Odds ratios for the risk of clinical high risk status as predicted by light and heavy smoking status model included tobacco use, marijuana use, alcohol use, age, ethnicity, academic performance, academic adjustment, depression, anxiety, social anxiety, daily stressors, life events and perceived discrimination as covariates. $* 95 \% \mathrm{Cl}>1$ categorization as ever-smoked $(\mathrm{HR}=1.3,95 \% \mathrm{Cl}=0.8-2.1)$ did not predict time to conversion.

\section{4 | DISCUSSION}

Persons at clinical high risk for psychosis are more likely to smoke than unaffected persons (Carney, Cotter, Bradshaw, Firth, \& Yung, 2016). Several factors associated with tobacco use, especially stressful life events, perceived discrimination, and substance use, were more common or more severe in clinical high risk subjects. When we included factors associated with smoking in a regression model, the clinical high risk subjects were no longer more likely to be smokers, suggesting that the proposed link between smoking and schizophrenia may be confounded by greater likelihood of co-morbid problems with substance use and higher stress.

To our knowledge, there is only one previous study of smoking and conversion risk in persons at clinical high risk; of 48 persons at high risk followed for 1 year, 67\% (4/6) of converters compared to $26 \%(11 / 42)$ of nonconverters were smokers (Fisher exact test $P$ value $=0.005)$ (Kristensen \& Cadenhead, 2007). However, marijuana use was also more common in converters than nonconverters (Fisher exact test $P$ value $=0.01$ ), and the four converters who smoked also used marijuana, making it impossible to separate the impact of smoking from that of marijuana on conversion. However, a second study reported higher prenatal nicotine exposure was associated with increased risk of subsequent schizophrenia $(O R=3.41,95 \% \mathrm{Cl}=1.86-6.24)$, controlled for maternal age, parental history of psychiatric disorder, and province of birth (Niemela et al., 2016).

Although many studies have identified an increased risk of psychosis conferred by smoking (Alderson \& Lawrie, 2015; Gage \& Munafo, 2015; Gurillo et al., 2015; Kendler et al., 2016; WiumAndersen et al., 2015), confounding variables continue to present a challenge. To this end, a recent study used sibling comparisons to account for both genetic and environmental variables. In this population study of 1.7 million Swedish offspring, maternal smoking during pregnancy was associated with an increased risk of severe mental illness in offspring. However, after comparing siblings, which accounted for all genetic and environmental confounders that make siblings similar, the relationship was weaker and no longer significant (Quinn et al., 2017). These findings, in combination with the results of our analysis, suggest that increased risk for the development of mental illness may be accounted for by a shared risk for both outcomes.

It is still conceivable that smoking could have a causal relationship to psychosis risk if clinical high risk persons who convert to psychosis have a different biological response to smoking than clinical high risk persons who do not convert. For example, although factors such as marijuana use, anxiety and trauma history may increase risk of clinical high risk symptoms and smoking, it may be that those clinical high risk smokers who also have a second psychosis-related vulnerability, such as impairment in antioxidant defence systems (linked to schizophrenia and challenged by smoking) develop psychosis. Future clinical high risk studies examining biomarkers linked to 


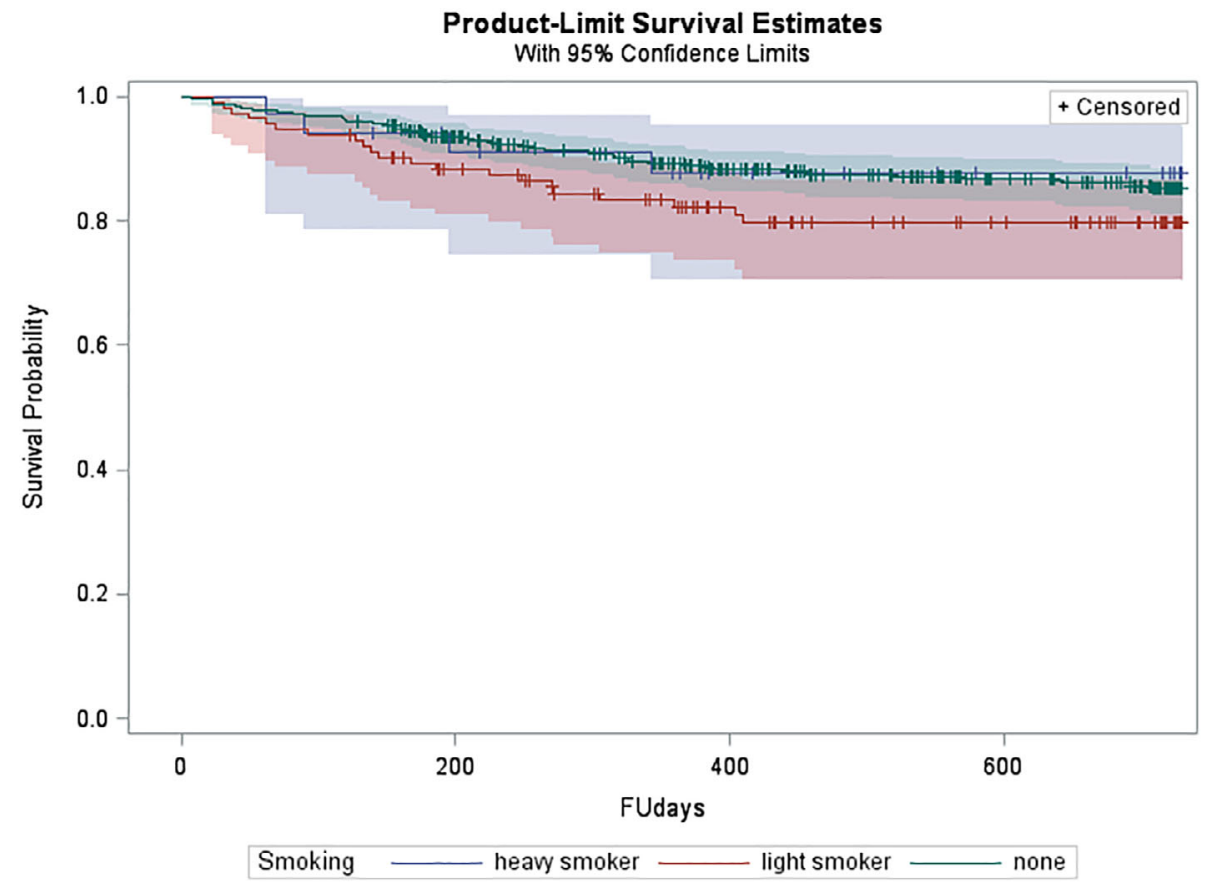

FIGURE 3 Kaplan-Meier survival curve stratified on smoking status for subjects at clinical high risk for conversion to psychosis

smoking may want to consider interactions with smoking as potential risk-modifiers.

Our findings also highlight a more general problem of the appropriate comparison groups in schizophrenia research. Persons with schizophrenia are likely to differ from the general population on numerous factors that are independent of the factors causing psychosis. Antipsychotic use is a commonly noted example, but this problem goes beyond prescribed medications. Similar to the smoking findings reported here, studies of clinical high risk subjects find many factors associated with schizophrenia are associated with a clinical high risk state, but not with conversion to psychosis, for example, trauma history (Addington et al., 2013; Stowkowy et al., 2016). Undetected confounding remains a barrier to understanding causal pathways for psychotic disorders, and the clinical high risk approach offers a strategy to address this problem.

In summary, our findings do not support a causal relationship between smoking and psychosis. At this point, interventions to address smoking in persons at clinical high risk for psychosis are needed, but the only clear rationale is the same as for the general population, that is to reduce risk of cardiovascular diseases and cancers. Future research is needed to understand the effect of smoking on individuals at clinical high risk for psychosis.

\section{CONTRIBUTORS}

Ward HB, Lawson MT, and Perkins DO performed the analysis and wrote the manuscript. Addington J, Bearden CE, Cadenhead KS, Cannon TD, Cornblatt BA, Jeffries CD, Mathalon DH, McGlashan TH, Seidman L, Tsuang MT, Walker EF, Woods SW, and Perkins DO designed and conducted the research.

\section{ACKNOWLEDGEMENTS}

We would like to thank: J. Stowkowy, T. Raedler, L. McGregor, D. Marulanda, L. Legere, L. Liu, C. Marshall, E. Falukozi, E. Fitton, L. McAusland and K. Smith (University of Calgary); T. Alderman, K. Shafer, I. Domingues, A. Hurria and H. Mirzakhanian (UCSD); B. Walsh, J. Saksa, N. Santamauro, A. Carlson, J. Kenney and B. Roman (Yale University); K. Woodberry, A. J. Giuliano, W. Stone, J. M. Rodenhiser, L. Tucker, R. Serur, G. Min and R. Szent-Imrey (Beth Israel Deaconess Medical Center/Harvard); C. Bearden, P. Bachman, J. Zinberg, S. DeSilva, A. Andaya and S. Uguryan (UCLA); J. Brasfield and H. Trotman (Emory University); A. Pelletier, K. Lansing, H. Mates, J. Nieri, B. Landaas, K. Graham, E. Rothman, J. Hurta, and Y. Sierra (University of North Carolina); and A. Auther, R. Carrion, M. McLaughlin and R. Olsen (Zucker Hillside Hospital). H.B.W., M.T.L., J.A., C.E.B., K.S.C., B.A.C., C.D.J., T.H.M., L.J.S., M.T.T., E.F.W., and S.W.W. report no financial relationships with commercial interests. T.D.C. and D.H.M. have consulted for Boeringer Ingelheim, and D.O.P. has consulted for Genentech, Sunovion, Otsuka, Lunbeck, and Janssen. This study was supported by the National Institute of Mental Health (NIMH) (grant U01 MH081984 to J.A.; grants U01 MH081928; P50 MH080272; Commonwealth of Massachusetts SCDMH82101008006 to L.J.S.; grants R01 MH60720, U01 MH082022 and K24 MH76191 to K.S.C.; grant U01 MH081902 to T.D.C.; P50 MH066286 [Prodromal Core] to C.E.B.; grant U01 MH082004 to D.O.P.; grant U01 MH081988 to E.F.W.; grant U01 MH082022 to S.W.W.; and U01 MH081857-05 grant to B.A.C.) and the National Institute of Environmental Health Sciences (NIEHS) grant T32ES007018 to M.T.W. The NIMH and NIEHS had no further role in study design; in the collection, analysis and interpretation of data; in the writing of the report; and in the decision to submit the paper for publication. 


\section{ORCID}

Heather B. Ward (D) https://orcid.org/0000-0003-2901-8004 Jean Addington (D) https://orcid.org/0000-0002-8298-0756 Kristin S. Cadenhead (D) https://orcid.org/0000-0002-5952-4605 Tyrone D. Cannon (D) https://orcid.org/0000-0002-5632-3154 Barbara A. Cornblatt (D) https://orcid.org/0000-0002-3194-6304 Daniel H. Mathalon (D) https://orcid.org/0000-0001-6090-4974 Thomas H. McGlashan (D) https://orcid.org/0000-0002-6130-5161 Larry J. Seidman (D) https://orcid.org/0000-0002-7731-9189 Ming T. Tsuang (D) https://orcid.org/0000-0002-0076-5340 Diana O. Perkins (D) https://orcid.org/0000-0001-9396-2206

\section{REFERENCES}

Addington, D., Addington, J., \& Matickatyndale, E. (1993). Assessing depression in schizophrenia-the Calgary depression scale. British Journal of Psychiatry, 163, 39-44.

Addington, J., Cadenhead, K. S., Cannon, T. D., Cornblatt, B., McGlashan, T. H., Perkins, D. O., ... Heinssen, R. (2007). North American Prodrome longitudinal study: A collaborative multisite approach to prodromal schizophrenia research. Schizophrenia Bulletin, 33(3), 665-672.

Addington, J., Cadenhead, K. S., Cornblatt, B. A., Mathalon, D. H., McGlashan, T. H., Perkins, D. O., ... Cannon, T. D. (2012). North American Prodrome longitudinal study (NAPLS 2): Overview and recruitment. Schizophrenia Research, 142(1-3), 77-82.

Addington, J., Stowkowy, J., Cadenhead, K. S., Cornblatt, B. A., McGlashan, T. H., Perkins, D. O., ... Cannon, T. D. (2013). Early traumatic experiences in those at clinical high risk for psychosis. Early Intervention in Psychiatry, 7(3), 300-305.

Alderson, H. L., \& Lawrie, S. M. (2015). Does cigarette smoking cause psychosis? Lancet Psychiatry, 2(8), 672-673.

Balk, E., Lynskey, M. T., \& Agrawal, A. (2009). The association between DSM-IV nicotine dependence and stressful life events in the National Epidemiologic Survey on Alcohol and Related Conditions. American Journal of Drug and Alcohol Abuse, 35(2), 85-90.

Brantley, P. J., Waggoner, C. D., Jones, G. N., \& Rappaport, N. B. (1987). A daily stress inventory: Development, reliability, and validity. Journal of Behavioral Medicine, 10(1), 61-74.

Cannon-Spoor, H. E., Potkin, S. G., \& Wyatt, R. J. (1982). Measurement of premorbid adjustment in chronic schizophrenia. Schizophrenia Bulletin, 8(3), 470-484.

Carney, R., Cotter, J., Bradshaw, T., Firth, J., \& Yung, A. R. (2016). Cardiometabolic risk factors in young people at ultra-high risk for psychosis: A systematic review and meta-analysis. Schizophrenia Research, 170(2-3), 290-300.

de Leon, J., \& Diaz, F. J. (2005). A meta-analysis of worldwide studies demonstrates an association between schizophrenia and tobacco smoking behaviors. Schizophrenia Research, 76(2-3), 135-157.

Dohrenwend, B. S., Krasnoff, L., Askenasy, A. R., \& Dohrenwend, B. P. (1978). Exemplification of a method for scaling life events: The Peri life events scale. Journal of Health and Social Behavior, 19(2), 205-229.

Drake, R. E., Mueser, K. T., \& McHugo, G. J. (1996b). Clinician rating scales: Alcohol use scale (AUS), drug use scale (DUS), and substance abuse treatment scale (SATS). In L. I. Sederer \& B. Dickey (Eds.), Outcomes assessment in clinical practice (pp. 113-116). Baltimore, MD: Williams and Wilkins.

Drake, R. E., Rosenberg, S. D., \& Mueser, K. T. (1996a). Assessing substance use disorder in persons with severe mental illness. New Directions for Mental Health Services, Summer(70), 3-17.

Gage, S. H., \& Munafo, M. R. (2015). Smoking as a causal risk factor for schizophrenia. Lancet Psychiatry, 2(9), 778-779.

Gurillo, P., Jauhar, S., Murray, R. M., \& MacCabe, J. H. (2015). Does tobacco use cause psychosis? Systematic review and meta-analysis. Lancet Psychiatry, 2(8), 718-725.
Janssen, I., Hanssen, M., Bak, M., Bijl, R. V., de Graaf, R., Vollebergh, W., ... van Os, J. (2003). Discrimination and delusional ideation. The British Journal of Psychiatry, 182, 71-76.

Janssen, I., Krabbendam, L., Bak, M., Hanssen, M., Vollebergh, W., de Graaf, R., \& van Os, J. (2004). Childhood abuse as a risk factor for psychotic experiences. Acta Psychiatrica Scandinavica, 109(1), 38-45.

Johnson, R. A., \& Hoffmann, J. P. (2000). Adolescent cigarette smoking in U.S. racial/ethnic subgroups: Findings from the National Education Longitudinal Study. Journal of Health and Social Behavior, 41(4), 392-407.

Kendler, K. S., Lonn, S. L., Sundquist, J., \& Sundquist, K. (2015). Smoking and schizophrenia in population cohorts of Swedish women and men: A prospective co-relative control study. The American Journal of Psychiatry, 172(11), 1092-1100.

Kendler, K. S., Ohlsson, H., Mezuk, B., Sundquist, K., \& Sundquist, J. (2016). A Swedish National Prospective and co-relative study of school achievement at age 16 , and risk for schizophrenia, other nonaffective psychosis, and Bipolar Illness. Schizophrenia Bulletin, 42(1), 77-86.

Kristensen, K., \& Cadenhead, K. S. (2007). Cannabis abuse and risk for psychosis in a prodromal sample. Psychiatry Research, 151(1-2), 151-154.

Kushner, M. G., Menary, K. R., Maurer, E. W., \& Thuras, P. (2012). Greater elevation in risk for nicotine dependence per pack of cigarettes smoked among those with an anxiety disorder. Journal of Studies on Alcohol and Drugs, 73(6), 920-924.

Leventhal, A. M., Japuntich, S. J., Piper, M. E., Jorenby, D. E., Schlam, T. R., \& Baker, T. B. (2012). Isolating the role of psychological dysfunction in smoking cessation: Relations of personality and psychopathology to attaining cessation milestones. Psychology of Addictive Behaviors, 26(4), 838-849.

Leventhal, A. M., \& Zvolensky, M. J. (2015). Anxiety, depression, and cigarette smoking: A transdiagnostic vulnerability framework to understanding emotion-smoking comorbidity. Psychological Bulletin, 141(1), $176-212$.

Liu, X. (2003). Cigarette smoking, life stress, and behavioral problems in Chinese adolescents. The Journal of Adolescent Health, 33(3), 189-192.

Lynch, J. W., Kaplan, G. A., \& Salonen, J. T. (1997). Why do poor people behave poorly? Variation in adult health behaviours and psychosocial characteristics by stages of the socioeconomic lifecourse. Social Science \& Medicine, 44(6), 809-819.

McGlashan, T. H., Walsh, B. C., \& Woods, S. W. (2010). The psychosis risk syndrome: Handbook for diagnosis and follow-up. New York: Oxford University Press.

Niemela, S., Sourander, A., Surcel, H. M., Hinkka-Yli-Salomaki, S., McKeague, I. W., Cheslack-Postava, K., \& Brown, A. S. (2016). Prenatal nicotine exposure and risk of schizophrenia among offspring in a national birth cohort. American Journal of Psychiatry, 173(8), 799-806.

Olivares, J., Garcia-Lopez, L. J., \& Hidalgo, M. D. (2001). The social phobia scale and the social interaction anxiety scale: Factor structure and reliability in a Spanish-speaking population. Journal of Psychoeducational Assessment, 19(1), 69-80.

O'Loughlin, J. L., Dugas, E. N., O'Loughlin, E. K., Karp, I., \& Sylvestre, M. P. (2014). Incidence and determinants of cigarette smoking initiation in young adults. Journal of Adolescent Health, 54(1), 26-U136.

Otten, F., Bosma, H., \& Swinkels, H. (1999). Job stress and smoking in the Dutch labour force. European Journal of Public Health, 9(1), 58-61.

Patton, G. C., Carlin, J. B., Coffey, C., Wolfe, R., Hibbert, M., \& Bowes, G. (1998). Depression, anxiety, and smoking initiation: A prospective study over 3 years. American Journal of Public Health, 88(10), 1518-1522.

Perkins, D. O., Jeffries, C. D., Cornblatt, B. A., Woods, S. W., Addington, J., Bearden, C. E., ... McGlashan, T. H. (2015). Severity of thought disorder predicts psychosis in persons at clinical high-risk. Schizophrenia Research, 169, 169-177.

Quinn, P. D., Rickert, M. E., Weibull, C. E., Johansson, A. L. V., Lichtenstein, P., Almqvist, C., ... D'Onofrio, B. M. (2017). Association between maternal smoking during pregnancy and severe mental illness in offspring. JAMA Psychiatry, 74(6), 589-596.

Riala, K., Hakko, H., Isohanni, M., Pouta, A., \& Rasanen, P. (2005). Is initiation of smoking associated with the prodromal phase of schizophrenia? Journal of Psychiatry \& Neuroscience, 30(1), 26-32. 
Sonntag, H., Wittchen, H. U., Hofler, M., Kessler, R. C., \& Stein, M. B. (2000). Are social fears and DSM-IV social anxiety disorder associated with smoking and nicotine dependence in adolescents and young adults? European Psychiatry, 15(1), 67-74.

Sorensen, H. J., Mortensen, E. L., Reinisch, J. M., \& Mednick, S. A. (2011). A prospective study of smoking in young women and risk of later psychiatric hospitalization. Nordic Journal of Psychiatry, 65(1), 3-8.

Stowkowy, J., Liu, L., Cadenhead, K. S., Cannon, T. D., Cornblatt, B. A., McGlashan, T. H., ... Addington, J. (2016). Early traumatic experiences, perceived discrimination and conversion to psychosis in those at clinical high risk for psychosis. Social Psychiatry and Psychiatric Epidemiology, 51(4), 497-503.

van Mastrigt, S., \& Addington, J. (2002). Assessment of premorbid function in first-episode schizophrenia: Modifications to the premorbid adjustment scale. Journal of Psychiatry \& Neuroscience, 27(2), 92-101.

Wechsler, D. (1999). Wechsler abbreviated scale of intelligence. San Antonio, TX: The Psychological Corporation.

Weiser, M., Reichenberg, A., Grotto, I., Yasvitzky, R., Rabinowitz, J., Lubin, G., ... Davidson, M. (2004). Higher rates of cigarette smoking in male adolescents before the onset of schizophrenia: $A$ historical-prospective cohort study. The American Journal of Psychiatry, 161(7), 1219-1223.
Wium-Andersen, M. K., Orsted, D. D., \& Nordestgaard, B. G. (2015). Tobacco smoking is causally associated with antipsychotic medication use and schizophrenia, but not with antidepressant medication use or depression. International Journal of Epidemiology, 44(2), 566-577.

Zammit, S., Allebeck, P., Dalman, C., Lundberg, I., Hemmingsson, T., \& Lewis, G. (2003). Investigating the association between cigarette smoking and schizophrenia in a cohort study. The American Journal of Psychiatry, 160(12), 2216-2221.

\section{SUPPORTING INFORMATION}

Additional supporting information may be found online in the Supporting Information section at the end of the article.

How to cite this article: Ward HB, Lawson MT, Addington J, et al. Tobacco use and psychosis risk in persons at clinical high risk. Early Intervention in Psychiatry. 2019;13:1173-1181. https://doi.org/10.1111/eip.12751 